\title{
Hyperbaric pressure does not affect the analgesia produced by nitrous oxide in the mouse
}

Hydrostatic pressure antagonizes some, but not all, of the phenomena associated with general anaesthesia. For example. while unconsciousness produced by general anaesthesia in a wide variery of species is reversed by compression, anaestheticinduced inhibition of synaptic transmission is potentiated by application of pressure. To date, the effect of pressure on analgesia has not been evaluated. In this study, hyperbaric pressure of 75 ata did not antagonize analgesia which had been produced by exposure of mice to 1.2 ata of nitrous oxide. However, the same hyperbaric pressure restored righting in animals which had been anaesthetized with 1.5 ata of nitrous oxide. These data add to the suggestion that the multiple effects of general anossthetics may be mediated at different loci.

\section{Key words}

ANALGESIA: measurement; HYPERBARIA: pressure reversal; THEORIES OF ANESTHESIA: pressure reversal, critical volume, multi-site expansion.

Department of Anesthesia and The Institute for Environmental Medicine, University of Pennsylvania Medical School, Philadelphia, PA 19104, USA.

Address correspondence to: Dr. Cohen, Department of Anesthesia, 774 Dulles, Hospital of the University of Pennsylvania, 3400 Spruce Street, Philadelphia, PA 19104, USA

Presented at the 1987 Meeting of the Society of Neurosurgical Anesthesia and Critical Care. A preliminary report of this work has been published as an abstract in Anesthesiology Review 14: 48-9, 1987.

Supported in part by NIH Grant GM 29628.
The ability of increased pressure to reverse unconsciousness produced by administration of general anaesthetics (pressure reversal) has been well documented since its first description over 40 years ago. ${ }^{1}$ Anaesthetic actions amenable to pressure reversal include loss of the righting reflex in the mouse produced by both nitrous oxide $^{2}$ ( 25 ata of helium increased $E D_{50}$ by 15 per cent) and isoflurane ${ }^{3}$ (12.5 ata was associated with a 27 per cent increase in $\mathrm{ED}_{50}$ ) recovery of swimming in tadpoles exposed to 0.25 per cent chloroform ${ }^{4}$ (complete narcotic reversal was observed at a hydrostatic pressure of 34 ata), and inhibition of axonal transmission in the rat superior cervical ganglion ${ }^{5}$ ( 35 ata reduced the inhibition produced by 2.4 per cent halothane by 30 per cent).

However, pressure does not antagonize all phenomena associated with general anaesthesia. For example, halothane's inhibition of synaptic transmission in the rat superior cervical ganglion is potentiated, rather than antagonized, by pressure; a decrease of five to ten per cent in post-ganglionic action potential is produced by 35 ata of belium, both in the presence and absence of halothane. ${ }^{5}$ Similarly, halothane's depression of the ciliary beat of Tetrahymena pyriformis is enhanced by 137 ata. ${ }^{6}$ Recent$l y$, it has been reported that halothane's inhibition of the oxygen uptake of rat liver mitochondria ${ }^{7}$ and intact green monkey kidney cells ${ }^{8}$ is not reversed by 50 ata of hydraulic pressure.

While there have been numerous studies of the action of pressure on anaesthetic-induced unconsciousness or loss of the righting reflex, its effect on other components of general anaesthesia (such as analgesia or suppression of reflex activity) has not been examined. Accordingly, the following study was undertaken.

Abbreviation: ata $=$ atmospheres absolute. Ambient pressure is 1 ata $=101.3 \mathrm{kPa}(760 \mathrm{mmHg} ; 14.7$ lb $\cdot$ in $^{-2}$ ) 


\section{Methods}

A total of 57 mice was studied in this investigation which was approved by our Institutional Animal Care and Use Committee. Each animal was used only once and then sacrificed. The project consisted of several studies which are detailed below.

Study \#1

In this study, designed to approximate the analgesic partial pressure of nitrous oxide, analgesia was evaluated in five female Swiss-Webster mice (studied individually) by observing their response to a noxious electrical stimulation of the tail. ${ }^{9}$ The maximum stimulus provided by a peripheral nerve stimulator (FB-800, MU Systems, Inc., Westmont, Illinois) was fed into the chamber through two wires which were wrapped around the loosely restrained mouse's tail. Electrolyte paste was applied to ensure a constant physical stimulus. ${ }^{10}$ The small chamber, made by the Institute for Environmental Medicine (volume approximately nine litres), was initially filled with oxygen at ambient pressure. After control observations, the chamber was sealed and nitrous oxide added during a one- to two-minute period to achieve partial pressures of $0.7,1.0$, and 1.4 ata, with pressurization always in this order. After waiting five minutes, analgesia was evaluated at each pressure of nitrous oxide.

\section{Study \#2}

The purpose of this phase of the investigation was to determine the minimum partial pressure of nitrous oxide which would result in certain analgesia. Mice were evaluated as described above at nitrous oxide partial pressures of 1.0,1.1, 1.2,1.3 and 1.4 ata. Five mice were exposed to each pressure of nitrous oxide; each mouse was studied only once; 25 mice were evaluated in this study.

\section{Study \#3}

After establishing the minimum analgesic partial pressure of nitrous oxide with 1.0 ata oxygen (MAPP), the effect of 75 ata on mice exposed to this pressure was evaluated in nine individual studies, each examining a single animal. Only one animal was studied at a time. After attaining MAPP, analgesia was verified as described above. The chamber was then pressurized with helium during a 30-minute period (chamber temperature was $31-34^{\circ} \mathrm{C}$ ) attaining a total pressure of $75 \mathrm{ata}$, and the response to electrical stimulation again observed. Since an all or none response was being observed, the binomial test ${ }^{1 k}$ was used to determine statistical significance of the findings.

\section{Study \#4}

In order to examine the effect of helium on the response to electrical stimulus in the absence of nitrous oxide, the chamber (initially filled with oxygen at ambient pressure) was compressed with helium to a total pressure of 75 ata and analgesia evaluated in three animals, each studied separately.

\section{Study \#5}

The purpose of this study was to determine the minimum partial pressure of nitrous oxide with 1.0 ata oxygen which would produce narcosis (MNPP) as determined by loss of the righting reflex. In three separate studies (two animals in each), unrestrained mice were observed for loss of the righting reflex during exposure to $1.1,1.3,1.5$ and 1.7 ata nitrous oxide. Each mouse was exposed to the four pressures investigated.

\section{Study \#6}

In this examination of pressure reversal of narcosis, six mice were studied individually to assess the ability of 75 ata to restore righting. In each study, MNPP was first attained; following verification of loss of the righting reflex, the chamber was compressed with helium to a total pressure of 75 ata as above, and the presence or absence of the righting reflex evaluated. The binomial test " was used to assess statistical significance.

\section{Study \#7}

Because of helium's high thermal conductivity, the effect of $I$ ata oxygen, 1.2 ata nitrous oxide and 73 ata helium on rectal temperature was evaluated in three mice while the chamber temperature remained at $31-34^{\circ} \mathrm{C}$.

\section{Results}

Study \#1

Studies conducted while the mice breathed air outside the chamber showed an obvious response of the animal (movement of the tail and body as well as vocalization) to electrical stimulus. Movement of the tail, body, and mouth accompanied electrical stimulus when the animals breathed nitrous oxide partial pressures of $0,0.7$, and 1.0 ata. Electrical stimuli no longer elicited a response when the mice were exposed to 1.4 ata nitrous oxide (Table I).

Study \#2

When determining MAPP, the electrical stimulus produced an obvious response in all mice exposed to 1.0 ata nitrous oxide. Four of the five mice breathing 1.1 ata nitrous oxide reacted to electrical stimulus; none breathing $1.2,1.3$ or 1.4 ata nitrous oxide evidenced response to this stimulus (Table II). The MAPP was thus determined to be 1.2 ata. 
TABLE [ Nitrous oxide and analgesia in the mouse

\begin{tabular}{lll}
\hline$N_{2} O(a t a)$ & $O_{2}$ (ata) & Response \\
\hline 0 & 1 & $5+$ \\
0.7 & 1 & $5+$ \\
1.0 & 1 & $5+$ \\
1.4 & 1 & $5-$ \\
\hline
\end{tabular}

Determination of the approximate partial pressure of nitrous oxide producing analgesia to electrical stimulus of the mouse tail. Five mice were studied at nitrous oxide partial pressures of $0,0.7,1,0$ and 1.4 ata. Each mouse was studied at atl four partial pressures being examined. Analgesia was not observed at partial pressures of 1.0 ata or less. Analgesia was produced in each of the five animals at a nitrous oxide partial pressure of 1.4 ata

$+=$ Obvious response to a noxious stimulus.

$-=$ No response to a noxious stimulus

\section{Study \#3}

When mice breathing 1.2 ata nitrous oxide were compressed with helium to a total pressure of 75 ata, there was no effect on analgesia (Table III). These findings were identical in each of the nine mice studied $(p<0.002)$.

\section{Study \#4}

In the presence of 74 ata helium and $I$ ata oxygen, the three mice each reacted to the noxious stimulus as they had when breathing oxygen at ambient pressure (Table III).

\section{Study \#5}

The righting reflex was lost in all mice at nitrous oxide partial pressures of 1.5 and 1.7 ata; it remained intact when the partial pressure was 1.1 or 1.3 ata. The MNPP was thus determined to be 1.5 ata.

\section{Study \#6}

When the partial pressure of nitrous oxide was maintained

TABLE II Determination of minimum analgesic partial pressure of nitrous oxide in the mouse

\begin{tabular}{lll}
\hline $\mathrm{N}_{2} \mathrm{O}(\mathrm{ata})$ & $\mathrm{O}_{2}$ (ata) & Response \\
\hline 1.0 & 1 & $5+$ \\
1.1 & 1 & $4+, 1-$ \\
1.2 & 1 & $5-$ \\
1.3 & 1 & $5-$ \\
1.4 & 1 & $5-$ \\
\hline
\end{tabular}

Determination of the minimum partial pressure required for cerain nitrous oxide-induced analgesia (MAPP) using electrical stimulus of the mouse tail. Twenty-five mice were studied, each at one of the five partial pressures being examined. Each animal was evaluated only once. No analgesia was observed at 1.0 ata. A partial pressure of 1.1 ata produced analgesia in 20 per cent of the animals. Aralgesia in all mice accompanied exposure to $1.2,1.3$ and 1.4 ata nitrous oxjde. $+=$ Obvious response to a noxious stimulus.

$-=$ Na response to a noxious stimulus.
TABLE III Effect of pressure on nitrous oxide-induced analgesia in the mouse

\begin{tabular}{llll}
\hline $\mathrm{N}_{2} \mathrm{O}(\mathrm{ata})$ & $\mathrm{He}(\mathrm{ata})$ & $\mathrm{O}_{2}$ (ata) & Response \\
\hline 0 & 0 & 1 & + \\
1.2 & 0 & 1 & - \\
1.2 & 73 & 1 & - \\
0 & 74 & 1 & + \\
\hline
\end{tabular}

Effect of pressure on nitrous oxide-induced analgesia. Analgesia produced by inhalation of 1.2 ata nitrous oxide (MAPP) was unaffected by compression with helium to a total pressure of 75 ata in each of the nine animals studied. Compression with helium in the absence of nitrous oxide did not produce analgesia in any of the three animals evaluated.

$+=$ Obvious response to a noxious stimulus.

$-=$ No response to a noxious stimulus.

at $1.5 \mathrm{ata}$, compression with heliurn to a total pressure of 75 ata restored the righting reflex in each of the six animals studied ( $p<0.02)$.

\section{Study \#7}

Finally, during a period of observation similar to that of study \#3, body temperature remained at $36-37^{\circ} \mathrm{C}$ during exposure to 1 ata oxygen, 1.2 ata nitrous oxide and 73 ata helium.

\section{Discussion}

The phenomenon of pressure reversal is the basis for two differing theories of anaesthesia. The critical volume hypothesis ${ }^{12}$ suggests that general anaesthesia is caused by expansion of a single vital hydrophobic site; pressure reversal results from recompression of this locus. However, the inability of pressure to produce equal antagonism of differing anaesthetics' inhibition of the righting reflex, and the fact that not all anaesthetic actions are reversed by pressure has suggested an altemate approach. The multi-site expansion hypothesis ${ }^{13}$ theorizes that general anaesthesia results from the expansion of differing sites which vary in their physical properties.

This investigation demonstrated that the analgesia produced by 1.2 ata nitrous oxide was not antagonized by 75 ata pressure. Loss of consciousness, i.e., general anaesthesia, was produced by inhalation of 1.5 ata nitrous oxide, a finding consistent with other observations that loss of the righting reflex in mice occurs at 1.47 ata of nitrous oxide. ${ }^{2}$ This behavioural change was reversed by the same pressure which had failed to antagonize nitrous oxide's analgesia. The present investigation thus suggests that analgesia may result from anaesthetic action at a site different from that responsible for altered consciousness.

Although helium does not produce narcosis even at high pressure, it is conceivable that its high thermal 
conductivity might have decreased the action of the electrical stimulus. However, this stimulus does not act through heat generation. Furthermore, compression with helium to a pressure of 75 ata did not result in any degree of analgesia in the absence of nitrous oxide.

It is conceivable that higher pressures of helium might have antagonized analgesia. Indeed, it is certainly possible that each of the myriad effects of general anesthesia (e.g., narcosis, analgesia, amnesia, neuromuscular function, myocardial contractility) might be reversed by application of differing partial pressures of an inert gas, indicating different dose-response relationships for them. The current study has dealt only with the contrasting effects of pressure on analgesia and narcosis. Further studies would clearly be needed to sort out the many other phenomena associated with general anaesthesia.

In conclusion, the data obtained in this study demonstrate that a pressure of 75 ata did not antagonize the analgesia produced by 1.2 ata of nitrous oxide in the mouse. The same pressure was able to restore consciousness in mice exposed to a higher pressure of nitrous oxide. These data add support to the multi-site expansion hypothesis.

\section{Acknowledgements}

I would like to express my thanks to Christian J. Lambertsen, M.D. and Robert Gelfand, M.E.E. for their encouragement. Charles Hires, B.A. provided invaluable assistance both in obtaining the small animal chamber and in designing the gauges and flowmeters enabling me to subject the animals to accurately measured pressures of nitrous oxide and helium. Supported in part by NIH GM 29628.

\section{References}

1 Johnson FH, Brown DES, Marsiand DA. Pressure reversal of the action of certain narcotics. J Cell Comp Physiol 1942; 20: 269-76.

2 Halsey MJ. Eger EI, Kent DW, Warne PJ. High-pressure studies of anesthesia; $I n$ : Molccular Mechanisms of Anesthesia, Fink BR (Ed). Raven Press, N.Y. 1975

3 Kent DW, Halsey MJ, Eger EI, Kent B. Isofluranc anesthesia and pressure antagonism in mice. Anesth Analg 1977; 56: 97-101.

4 Halsey $M J$, Wardley-Smith $B$. Pressure reversal of narcosis produced by anaesthetics, narcotics and tranquillisers. Nature 1975; 257: 811-3.

5 Kendig JJ, Trudell JR, Cohen EN. Effects of pressure and anesthetics on conduction and synaptic transmission. J Pharmacol Exper Therap 1975; 195: 216-24.
6 Pope WDB, Jones AJ, Halsey MJ, Nunn JF. Pressure enhancement of the depressant effect of halothane on cilial beat. Can Anaesth Soc J 1978; 25: 319-22.

7 Cohen PJ. Effect of hydrostatic pressure on halothaneinduced depression of mitochondrial respiration. Life Sciences $1983 ; 32: 1647-50$.

8 Cohen PJ, Bedows E, Brabec MJ, Knight PR. Hyperbaric pressure of 51 atmospheres is without effect on the depression of oxygen uptake in kidney tissue culture produced by halothane. Life Sciences 1985; 37: 1221-4.

9 Schulz A, Katz R, Pavlin E. A comparison of ulnar nerve tetanic stimulation and clamping of anterior axillary fold to surgical incision for the determination of MAC. Anesthesjology 1987; 67: A669.

10 Tursky $B$, Watson $P D$. Controlled physical and subjective intensities of electric shock. Psychophysiology 1964; 1: 151-62.

11 Mainland $D$. Elementary Medical Statistics. Philadelphia, WB Saunders Company, 1952.

12 Miller KW, Paton WDM, Smith RA, Smith, EB. The pressure rcversal of general anesthesia and the critical volume hypothesis. Molec Pharmacol 1973; 9: 131-43.

13 Haisey MJ, Wardley-Smith B, Green CJ. Pressure reversal of general anaesthesia: a multi-site expansion hypothesis. Br J Anaesth 1978; 50: 1091-7.

\section{Résumé}

La pression hydrostatique antagonise quelques-uns mais pas tous les phénomènes associés à l'anesthésie générale. Alors que l'état d'inconscience par exemple produit par l'anesthésie générale chez une grande variété d'espèces est antagonisé par la compression, linhibition de la transmission synaptique induite par l'anesthésie est augmentée par l'application de la pression. A date, les effets de la pression sur l'analgésie n'ont pas encore été évalués. Dans cette étude, la pression hyperbare de 75 ata n'a pas antagonisé l'analgésie produte en exposant des souris d̀ 1.2 ata de protoxyde d'azote. Cependant, la même pression hyperbare a restauré le "righting refflexe" chez les animaux qui ont été anesthésiés avec 1.5 ata de protoxyde d'azote. Ces données suggèrent que les effets multiples de l'anesthésie générale sont générés par des centres différents. 